2009, 113, 5031-5034

Published on Web 03/06/2009

\title{
Direct Synthesis of Zr-Doped Ceria Nanotubes
}

\author{
Ying-Chen Chen, Kuei-Bo Chen, Chi-Shen Lee,* and M. C. Lin \\ Department of Applied Chemistry, National Chiao Tung University, 1001 University Road, \\ Hsinchu 30010, Taiwan
}

Received: November 29, 2008; Revised Manuscript Received: February 18, 2009

\begin{abstract}
$\mathrm{Zr}$-doped ceria nanotubes $\left(\mathrm{Zr}_{\mathrm{x}} \mathrm{Ce}_{1-x} \mathrm{O}_{2}\right)$ were obtained in a high yield from a hydrothermal reaction in an aqueous solution of $\mathrm{NaOH}$ with $\mathrm{Ce}\left(\mathrm{NO}_{3}\right)_{3} \cdot 6 \mathrm{H}_{2} \mathrm{O}$ and $\mathrm{ZrO}_{2}$ powder in a small proportion. The morphology and crystalline structure were characterized with X-ray diffraction, a scanning electron microscope, and a transmission electron microscope. Mechanisms for the growth of $\mathrm{Zr}$-doped ceria nanotubes are proposed based on the Kirkendall effect; the formation of the tubular structure is strongly dependent on the precursor. This is the first report of a direct synthesis of cerium-oxide nanotubes in high yield. The surface area of the nanotubes is $76 \mathrm{~m}^{2} / \mathrm{g}$ and their average pore size is $\sim 52.2 \mathrm{~nm}$. Catalytic measurements show that the nanotubes as synthesized are active for an oxygen-storage capacity and for ethanol reforming.
\end{abstract}

The synthesis of metal-oxide nanocrystals with specific shapes has attracted considerable attention because of their distinctive properties and extensive applications that include photoluminescence, batteries, gas sensors, magnetic media, and catalysis. ${ }^{1-5}$ Among these materials, ceria is attractive because it exhibits a large capacity for the storage of oxygen ${ }^{6,7}$ (OSC) and serves as a solid electrolyte or anode material in solid-oxide fuel cells, ${ }^{8-12}$ oxygen sensor, ${ }^{13}$ ultraviolet absorber, ${ }^{14,15}$ and catalyst for various reactions. ${ }^{16}$ Dispersion of a catalytically active metal and ceriumoxide nanoparticles throughout an alumina support of large surface area has been reported to enhance the catalytic performance of the ethanol-reforming reaction. ${ }^{17,18}$ For the utilization of cerium oxide as a catalyst, a simple and effective technique to prepare it with both a large surface area and a controlled shape is needed. Shape-controlling syntheses of cerium oxide in various forms including particle, ${ }^{19}$ rod, ${ }^{20-23}$ cube,,${ }^{18,24}$ hollow sphere, ${ }^{25}$ wire, ${ }^{26}$ flowerlike, ${ }^{27,28}$ and nanotube ${ }^{29-32}$ have been reported. Among several methods developed recently for the synthesis of ceria nanotubes, Han et al. demonstrated the use of precipitation and an aging process to prepare $\mathrm{CeO}_{2}$ nanotubes; their method requires protracted aging $(45 \mathrm{~d})$, and the product contains $\mathrm{CeO}_{2}$ nanostructures in both rod and tube forms. ${ }^{31}$ Tang and co-workers described another method to prepare $\mathrm{CeO}_{2}$ nanotubes on annealing $\mathrm{Ce}(\mathrm{OH})_{3}$ nanorods under reducing conditions, ${ }^{32}$ the entire process requires operation under an inert atmosphere, and the major product has a nanorod instead of a nanotube form. Zhou and co-workers reported the synthesis of $\mathrm{CeO}_{2}$ nanotubes using $\mathrm{H}_{2} \mathrm{O}_{2}$ to etch $\mathrm{Ce}(\mathrm{OH})_{3}$ nanorods, ${ }^{31}$ but the product contains $\mathrm{CeO}_{2}$ nanomaterial in both tube and particle forms. Sun and co-workers reported the use of $\mathrm{Ce}(\mathrm{OH}) \mathrm{CO}_{3}$ nanorods as a precursor to synthesize a $\mathrm{CeO}_{2}$ nanomaterial in tube form in alkaline solutions. ${ }^{32}$ These approaches to synthesing cerium oxide nanotubes typically require protracted reaction, templating materials (e.g., AAO), surfactants (e.g., PEG), or multiple steps during which the reaction condition is difficult

* To whom correspondence should be addressed. Tel.: 886-3-5131332. Fax: 886-3-5723764. E-mail: chishen@ mail.nctu.edu.tw. to control. For the solid-solution phase, $\mathrm{Zr}_{x} \mathrm{Ce}_{1-x} \mathrm{O}_{2}$, various authors have described methods for the synthesis of mesoporous and nanocage forms ${ }^{25,33}$ but there seems to be no report regarding the direct synthesis of $\mathrm{Zr}$-doped $\mathrm{CeO}_{2}$ nanotubes with a high yield. Here we report a facile approach for the synthesis of $\mathrm{Zr}_{x} \mathrm{Ce}_{1-x} \mathrm{O}_{2}$ nanotubes.

In a typical synthesis, $\mathrm{Ce}\left(\mathrm{NO}_{3}\right)_{3} \cdot 6 \mathrm{H}_{2} \mathrm{O}(0.4 \mathrm{~g})$ and $\mathrm{ZrO}_{2}$ (powder, $0.01 \mathrm{~g}$ ) were dispersed in $\mathrm{NaOH}(15 \mathrm{M}, \sim 16 \mathrm{~mL}$ ) solution under stirring near $295 \mathrm{~K}$ for $10 \mathrm{~min}$; the mixture was transferred into an autoclave $(25 \mathrm{~mL}$, diluted to $80 \%$ of the capacity with distilled water), which was sealed and maintained at $100-200{ }^{\circ} \mathrm{C}$ for $48 \mathrm{~h}$, followed by cooling naturally to ambient temperature. The white precipitate was washed several times with deionized water, collected by filtration, and dried in air. The yield of the product was estimated to be $\sim 90 \%$ based on the initial mass of $\mathrm{Ce}\left(\mathrm{NO}_{3}\right)_{3} \cdot 6 \mathrm{H}_{2} \mathrm{O}$. The crystal phase was determined with powder X-ray diffraction (XRD, Bruker D8Advance, $\mathrm{Cu} \mathrm{K} \alpha$ radiation). Structural and compositional information for the product material was obtained with a scanning electron microscope (SEM, Hitachi S-4700I), a transmission electron microscope, selected-area electron diffraction (TEM/SAED, JEM-2010F), an energy-dispersive X-ray spectrometer (HRTEM/EDX, JEM-2010F), an inductively coupled plasma-mass spectrometer (ICP-MS, Perkin-Elmer SCIEX ELAN 5000), a UV-vis spectrophotometer (Shimadzu UV1601). Analyses of surface area and pore size were carried out with Quantachrome. The catalytic activity was investigated by temperature-programmed reduction (TPR) with $\mathrm{H}_{2}$ and with ethanol-reforming analyses using a GC-MS system (Thermo Trace GC 2000). Reactions with various $\mathrm{Zr}$ precursors and reaction conditions were performed for the synthesis of $\mathrm{Zr}$-doped cerria nanomaterials. The synthetic procedures were kept constant; the results show that only the precursor $\mathrm{ZrO}_{2}$ yields the desired nanotube form. The duration of reaction time, temperature, and concentration of $\mathrm{NaOH}$ have no effect on the morphology. For reaction with high $\mathrm{Zr} / \mathrm{Ce}$ ratio, the products, based on the powder XRD and SEM, showed no nanotube form 

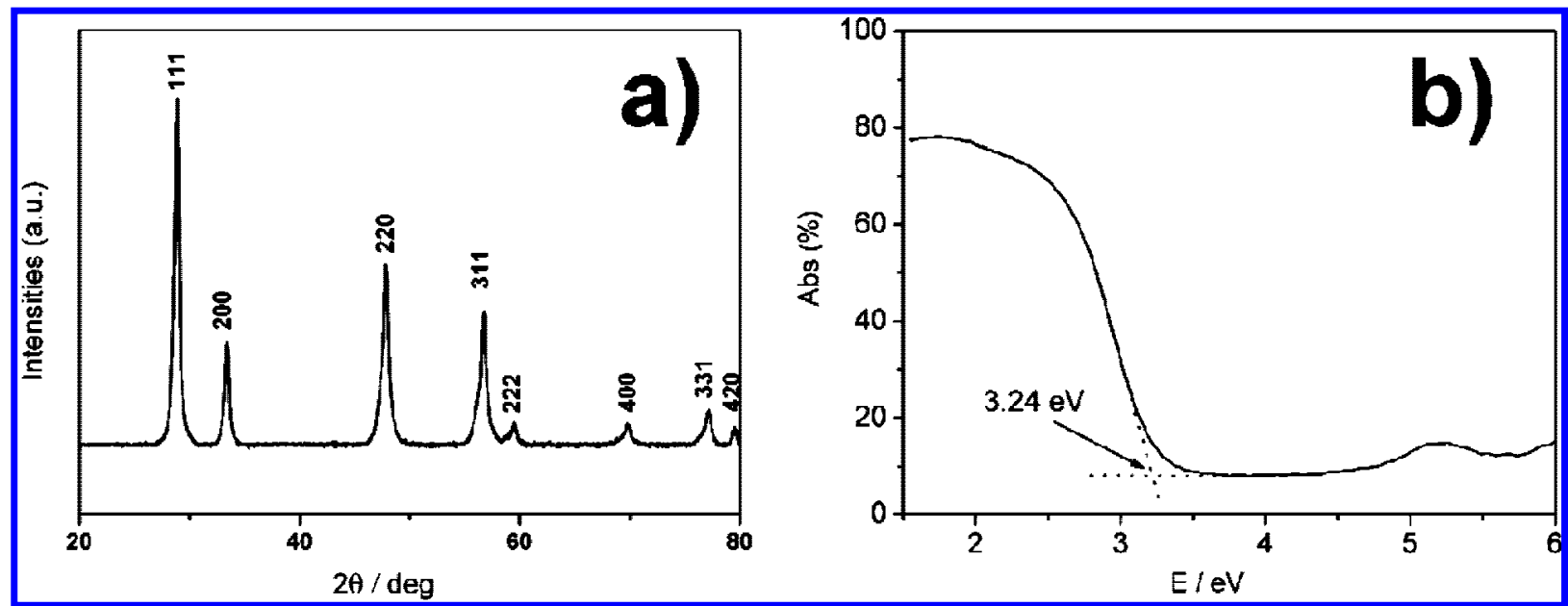

Figure 1. (a) X-ray diffraction pattern of Zr-doped ceria nanotubes, with indexes of X-ray features labeled. (b) Diffuse reflectance spectra of Zr-doped ceria nanotubes.

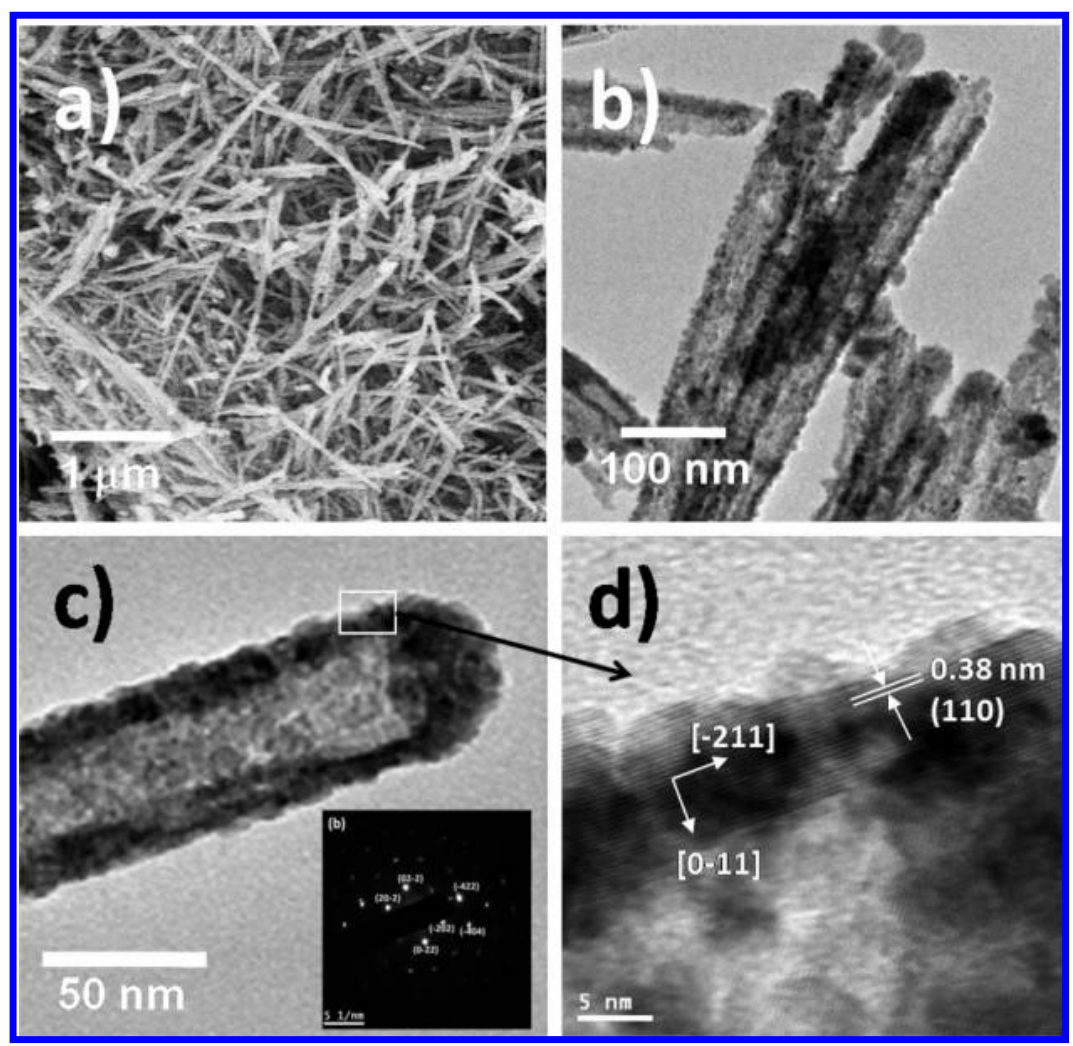

Figure 2. (a) SEM and (b) TEM images of Zr-doped ceria nanotubes. (c) TEM and selective-area electron-diffraction pattern (SAED, inset) of a nanotube. (d) HRTEM image of a portion of nanotube from (c) showing a domain of a single crystal.

and generally yielded a mixture of $\mathrm{CeO}_{2}, \mathrm{ZrO}_{2}$ with varied morphology (Table S1).

The powder XRD pattern for the product as synthesized is shown in Figure 1. In general, all diffraction features exhibit wide signals, indicative of small particles. The reflections were indexed to the cubic $\mathrm{CeO}_{2}$ structure $(a=5.411(1), F m \overline{3} m$ (No. 225), cubic, JCPDS 78-0694), in close agreement with the literature value $a=5.411 \AA$; no signal of an impurity phase was detected. The UV spectrum of the as-synthesized nanotubes measured in ethanol suspensions exhibited an intense absorption at $330 \mathrm{~nm}$; the band gap of the nanotubes as synthesized is accordingly calculated to be $3.24 \mathrm{eV}$ (Figure 1b). The XPS spectrum of the sample as synthesized exhibits the core levels of $\mathrm{Ce}(3 \mathrm{~d}), \mathrm{Ce}(4 \mathrm{~d}), \mathrm{Zr}(3 \mathrm{~s}), \mathrm{Zr}(3 \mathrm{p}), \mathrm{Zr}(3 \mathrm{~d})$, and $\mathrm{O}(1 \mathrm{~s})$; the $\mathrm{Ce}(3 \mathrm{~d})$ spectrum shows small contributions of $v^{\prime}$ and $u^{\prime}$ bands from
SCHEME 1: Schematic Illustration of the Transformation from Nanorod to Nanotube of $\mathrm{Zr}_{x} \mathrm{Ce}_{1-x} \mathrm{O}_{2}$ Based on the Kirkendall Effect

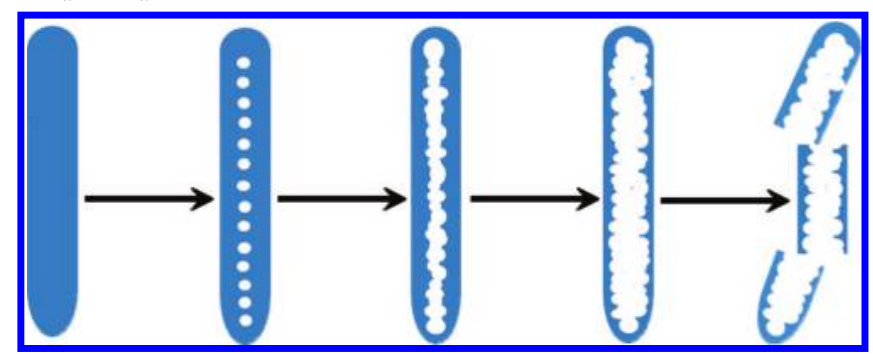

the $\mathrm{Ce}\left(3 \mathrm{~d}_{5 / 2}\right)$ and $\mathrm{Ce}\left(3 \mathrm{~d}_{3 / 2}\right)$ ionizations of $\mathrm{Ce}^{3+}$. The result indicates that the chemical valence of cerium on the surface of 


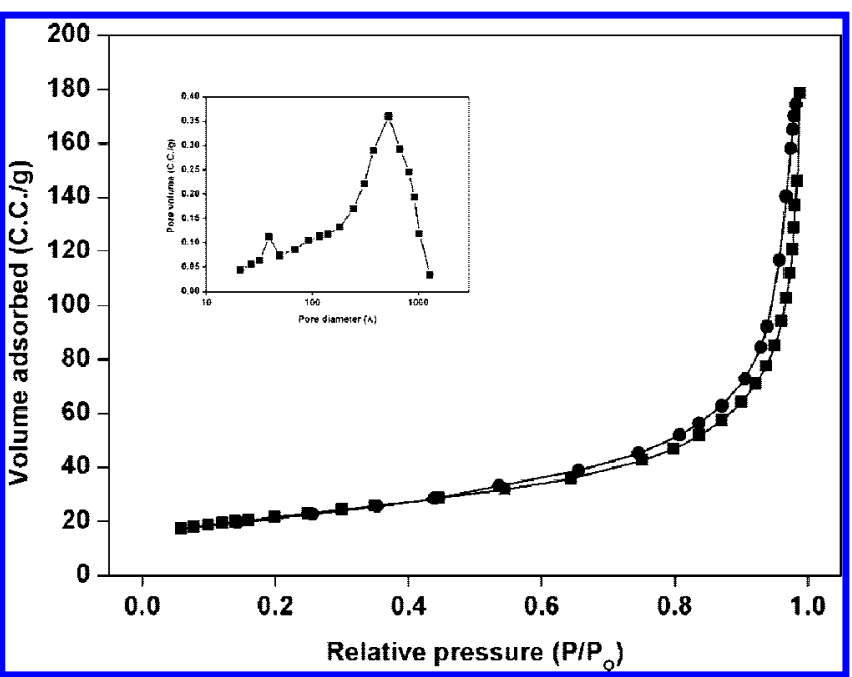

Figure 3. Nitrogen adsorption-desorption isotherms and the corresponding curves for the distribution of $\mathrm{BJH}$ pore size (inset) of $\mathrm{Zr}$ doped ceria nanotubes.

the $\mathrm{Zr}$-doped ceria nanotube is mainly $\mathrm{Ce}^{4+}$ with $\mathrm{Ce}^{3+}$ in a small proportion (Figure $\mathrm{S} 1$ ). ${ }^{34}$

The hydrothermal reaction of $\mathrm{Ce}\left(\mathrm{NO}_{3}\right)_{3} \cdot 6 \mathrm{H}_{2} \mathrm{O}$ with $\mathrm{ZrO}_{2}$ in a small proportion at $150{ }^{\circ} \mathrm{C}$ yielded much nanomaterial in rod form, as evident from the scanning-electron-microscope (SEM) image (Figure 2a). The TEM images (HRTEM) in Figure 2b indicate that most products dispersed on the copper TEM grids has an open-ended nanotube morphology. The nanotubes are uniform with average lengths up to several hundred $\mathrm{nm}$. The nanotubes have inner diameter in a range $30-50 \mathrm{~nm}$; the wall thickness is about $15 \pm 5 \mathrm{~nm}$. A TEM image of a nanotube with a round tip and a length greater than $200 \mathrm{~nm}$ is shown in Figure $2 c$. The granularity and porosity of the tube walls indicate that the tubes as obtained consist of many $\mathrm{CeO}_{2}$ nanoparticles. The selected-area-diffraction (SAED) pattern (inset of Figure 2c) demonstrates a domain of a single-crystalline part, and the high-resolution TEM image shown in Figure 2d reveals clear layer fringes along the tube wall with a layer separation approximately $3.8 \AA$ for the (110) planes. Elemental analyses with energy-dispersive X-ray spectra (EDS) and ICP mass tests reveal a small proportion of $\mathrm{Zr}$ with atomic ratios $\mathrm{Ce} / \mathrm{Zr} 0.99 /$ 0.01 for EDS and $0.97 / 0.03$ for ICP-mass (Figure S2). The results indicate that the $\mathrm{Zr}$ content is much smaller than the reaction composition $\sim 7$ atom $\%$, indicating that most $\mathrm{Zr}$ is not incorporated into the nanotube. The entire morphology evolution might be derived from the Kirkendall effect (see Scheme 1). ${ }^{25,35,36}$ The reaction initially yielded $\mathrm{Zr}_{x} \mathrm{Ce}_{1-x}(\mathrm{OH})_{3}$ in a rod form ${ }^{37}$ the $\mathrm{Zr}^{4+}$ ions may act as the catalyst that promote the diffuse rate of $\mathrm{Ce}^{3+} / \mathrm{Ce}^{4+}$ ions inside the nanorod; the metal hydroxide nanorods were gradually decompose to form $\mathrm{Zr}_{x} \mathrm{Ce}_{1-x} \mathrm{O}_{2}$ nanotubes according to a partial oxidation of $\mathrm{Ce}^{3+}$ and differential rate of diffusion between $\mathrm{Ce}^{4+}$ and $\mathrm{Ce}^{3+}$ ions inside the material. ${ }^{31}$

Figure 3 shows nitrogen adsorption-desorption isotherms and the corresponding distributions of pore size of the $\mathrm{Zr}$-doped ceria nanotubes. The isotherm curve evidently shows a hysteresis loop for relative pressures over a wide range. The BET (BrunauerEmmett-Teller) surface area of nanotubes as synthesized was $76 \mathrm{~m}^{2} / \mathrm{g}$. The curve for the distribution of pore size (inset of Figure 3), obtained with the Barrett-Joyner-Halenda (BJH) method using the adsorption branches of the isotherms, is centered about $\sim 52 \mathrm{~nm}$, consistent with the observed size from TEM tests. The subsidiary maximum at $\sim 3.8 \mathrm{~nm}$ may be due to the voids formed on the surface of a nanotube. ${ }^{38}$ Such a large surface area and pore size is comparable to previously reported $\mathrm{CeO}_{2}$ nanotube materials, obtained from $\mathrm{Ce}(\mathrm{OH}) \mathrm{CO}_{3}$ nanorods. ${ }^{32}$ The results indicate clearly that the surface area and porosity of the nanomaterials as synthesized are significantly superior to those of bulk $\mathrm{CeO}_{2}$ materials.

Ceria might be used as an oxygen-transfer component in redox catalysis for its excellent oxygen storage capacity (OSC). ${ }^{39}$ To characterize the OSC of the $\mathrm{Zr}$-doped ceria nanotubes, we performed temperature-programmed reduction (TPR) with $\mathrm{H}_{2}$ to obtain the result shown in Figure 4a. The reduction profile shows two broad maxima and a further reduction maximum above $700{ }^{\circ} \mathrm{C}$; the former features at 354 and $474{ }^{\circ} \mathrm{C}$ are attributed to a global process corresponding to the consumption of surface oxygen species, whereas the maximum at $825{ }^{\circ} \mathrm{C}$ reflects the bulk reduction. The area under the low-temperature curve can be used to estimate the oxygen that contributes to the reduction during the TPR operation. A quantitative evaluation of the low-temperature reduction feature (below $620^{\circ} \mathrm{C}$, representation for OSC) reveals that hydrogen consumed by $\mathrm{Zr}$ doped ceria nanotubes is $984 \mu \mathrm{mol} \mathrm{H}_{2}$ per g. ${ }^{31,40,41}$ The effect of as-synthesized nanotubes on $\mathrm{H}_{2}$ selectivity $\left(\mathrm{S}_{\mathrm{H}_{2}}\right)$ in ethanol reforming was tested using catalysts of $5 \mathrm{wt} \% \mathrm{Ru} / \mathrm{Zr}$-doped ceria nanotubes (catalyst 1) and $5 \mathrm{wt} \% \mathrm{Ru} / \mathrm{Zr}_{0.03} \mathrm{Ce}_{0.97} \mathrm{O}_{2}$ nanoparticles (catalyst 2) using porous $\mathrm{Al}_{2} \mathrm{O}_{3}$ as support, according to the literature scheme. The hydrogen selectivity $\left(\mathrm{S}_{\mathrm{H}_{2}}\right)$

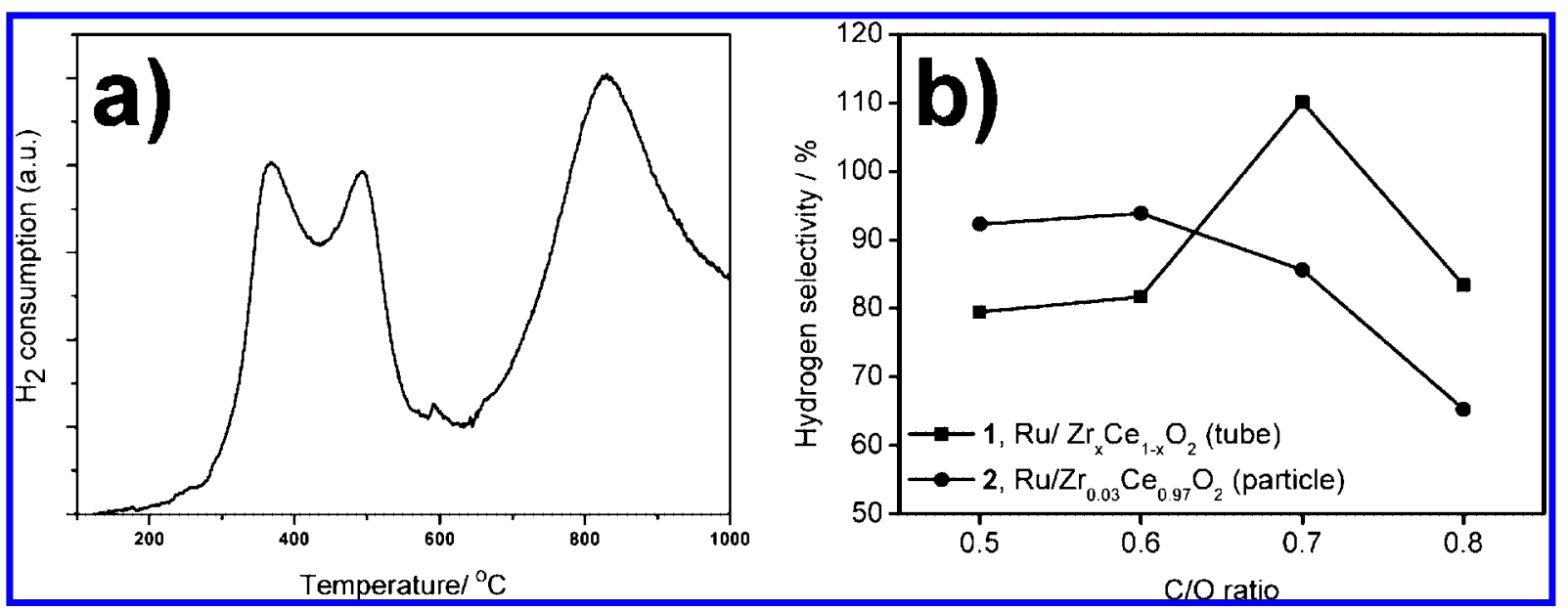

Figure 4. (a) TPR profile of $\mathrm{Zr}$-doped ceria nanotubes. (b) Hydrogen selectivity as a function of $\mathrm{C} / \mathrm{O}$ ratio obtained over catalysts $\mathbf{1}$ and 2 (5 wt $\% \mathrm{Ru} /\left(\mathrm{Zr}\right.$-doped cerria nanotubes or $\mathrm{Zr}_{0.03} \mathrm{Ce}_{0.97} \mathrm{O}_{2}$ particles). 
is defined as the molar ratio of the product $\mathrm{H}_{2}$ to the hydrogen production per mole of ethanol. The effect of the $\mathrm{C} / \mathrm{O}$ ratio on the catalytic performance of catalysts is shown in Figure $4 \mathrm{~b}$ with the $\mathrm{C} / \mathrm{O}$ ratio varied from 0.4 to 0.8 . The results indicate that, for catalyst $\mathbf{1}, \mathrm{S}_{\mathrm{H}_{2}}$ increased gradually on increasing $\mathrm{C} / \mathrm{O}$ to attain a maximum value $110 \%$ at $\mathrm{C} / \mathrm{O}=0.7$, which is larger than the maximum $\mathrm{S}_{\mathrm{H}_{2}}$ of catalyst $2\left(\mathrm{~S}_{\mathrm{H}_{2}}=90 \%\right.$ at $\mathrm{C} / \mathrm{O}$ ratio $\sim 0.6) . \mathrm{S}_{\mathrm{H}_{2}}$ of catalyst 1 decreased sharply from 110 to $60 \%$ upon altering the $\mathrm{C} / \mathrm{O}$ ratio from 0.7 to 0.8 , whereas $\mathrm{SH}_{2}$ of catalyst 2 decreased from 90 to $70 \%$. A catalyst with $\mathrm{Zr}$-doped ceria nanotubes is evidently more active than $\mathrm{CeO}_{2}$ particles for the conversion of ethanol to hydrogen, which might be due to the fact that $\mathrm{CeO}_{2}$ nanotubes contain a greater exposed surface of $\{100\}$ and $\{110\}$ facets than $\mathrm{CeO}_{2}$ nanoparticles. ${ }^{18}$

In conclusion, Zr-doped ceria nanotubes were synthesized with a direct hydrothermal reaction using $\mathrm{ZrO}_{2}$ in a small proportion to assist the formation of nanotubes. The possible mechanism may be described by the Kirkendall effect, and the formation of the tubular structure depends strongly on the precursor, rather than on the effect of the concentration of base. This reaction route significantly diminishes the duration of synthesis of Zr-doped ceria nanotubes. The product as synthesized exhibits a large surface area and a large pore size, and is highly active for hydrogen reduction and ethanol reforming relative to bulk material; the product might thus be used as a highly active catalyst. The results demonstrate that the direct synthesis of $\mathrm{Zr}$-doped ceria nanotubes with a large surface area and a large pore size indicates potential applications in catalysis. We expect this method to be applicable to the preparation of diverse metal-oxide nanotubes from suitable precursors.

Acknowledgment. For technical assistance, we thank Professors Chia-Ming Yang for BET measurements and Professor Teng-Ming Chen for UV measurements. The Institute of Nuclear Energy Research, Atomic Energy Council, Taiwan (Contract NL940251) and National Science Council (Contracts NSC942113-M-009-012, 94-2120-M-009-014) supported this research. M.C.L. acknowledges Taiwan Semiconductor Manufacturing Co. for the TSMC distinguished professorship and Taiwan National Science Council for the Distinguished Visiting Professorship at National Chiao Tung University.

Supporting Information Available: Details of experimental procedures and additional XPS spectra, and SEM/TEM and EDS/ICP-mass results for $\mathrm{Zr}$-doped ceria nanotubes. This material is available free of charge via the Internet at http:// pubs.acs.org.

\section{References and Notes}

(1) Fernández-Garcá, M.; Martínez-Arias, A.; Hanson, J. C.; Rodriguez, J. A. Chem. Rev. 2004, 104, 4063-4104.

(2) Murray, R. W. Chem. Rev. 2008, 108, 2688-2720.

(3) Laurent, S.; Forge, D.; Port, M.; Roch, A.; Robic, C.; Elst, L. V.; Muller, R. N. Chem. Rev. 2008, 108, 2064-2110.

(4) Jeong, U.; Teng, X.; Wang, Y.; Yang, H.; Xia, Y. Adv. Mater. 2007, 19, 33-60.

(5) Franke, M. E.; Koplin, T. J.; Simon, U. Small 2006, 2, 36-50.
(6) Mai, H.-X.; Sun, L.-D.; Zhang, Y.-W.; Si, R.; Feng, W.; Zhang, H.-P.; Liu, H.-C.; Yan, C.-H. J. Phvs. Chem. B 2005, 109, 24380.

(7) Campbell, C. T.; Peden, C. H. F. Science 2005, 309, 713.

(8) Gasteiger, H. A.; Lamm, A.; Vielstich, W. Handbook of Fuel Cells: Fundamentals, Technology, and Applications; Wiley: Chichester, England; New York, 2003.

(9) Hoogers, G. Fuel Cell Technology Handbook; CRC Press: Boca Raton, FL, 2003.

(10) Larminie, J.; Dicks, A. Fuel Cell Systems Explained, 2nd ed.; J. Wiley: Chichester, West Sussex, 2003.

(11) Singhal, S. C.; Kendall, K. High-Temperature Solid Oxide Fuel Cells: Fundamentals, Design and Applications; Elsevier: Oxford; New York, 2003.

(12) Zhang, Y.; Zha, S.; Liu, M. Adv. Mater. 2005, 17, 487.

(13) Jasinski, P.; Suzuki, T.; Anderson, H. U. Sens. Actuators, B 2003, $95,73-77$.

(14) Masui, T.; Fujiwara, K.; Machida, K. I.; Adachi, G. Y. Chem. Mater. 1997, 9, 2197.

(15) Li, R. X.; Yabe, S.; Yamashita, M.; Momose, S.; Yoshida, S.; Yin, S.; Sato, T. Solid State Ionics 2002, 151, 235.

(16) Trovarelli, A. Catalvsis by Ceria and Related Materials; Imperial College Press: London, 2002.

(17) Deluga, G. A.; Salge, J. R.; Schmidt, L. D.; Verykios, X. E. Science 2004, 303, 993-997.

(18) Hsiao, W. I.; Lin, Y. S.; Chen, Y. C.; Lee, C. S. Chem. Phvs. Lett. 2007, 441, 294-299.

(19) Niederberger, M. Acc. Chem. Res. 2007, 40, 793-800.

(20) Kuiry, S. C.; Patil, S. D.; Deshpande, S.; Seal, S. J. Phvs. Chem. $\underline{B}$ 2005, 109, 6936.

(21) Vantomme, A.; Yuan, Z.-Y.; Du, G.; Su, B.-L. Langmuir 2005, 21,1132 .

(22) Sun, C.; Li, H.; Wang, Z.; Chen, L.; Huang, X. Chem. Lett. 2004, $33,662-663$.

(23) Sun, C.; Li, H.; Zhang, H.; Wang, Z.; Chen, L. Nanotechnology 2005, 16, 1454-1463.

(24) Ho, C.; Yu, J. C.; Kwong, T.; Mak, A. C.; Lai, S. Chem. Mater. 2005, 17, 4514-4522.

(25) Liang, X.; Wang, X.; Zhuang, Y.; Xu, B.; Kuang, S.; Li, Y. J.Am. Chem. Soc. 2008, 130, 2736-2737.

(26) Yada, M.; Sakaji, S.; Torikai, T.; Watari, T.; Furuta, S.; Katsuki, H. Adv. Mater. 2004, 16, 1222.

(27) Sun, C.; Sun, J.; Xiao, G.; Zhang, H.; Qiu, X.; Li, H.; Chen, L. J. Phvs. Chem. B 2006, 110, 13445-13452.

(28) Sun, C.; Li, H.; Chen, L. J. Phys. Chem. Solids 2007, 68, 17851790.

(29) Tang, C.; Bando, Y.; Liu, B.; Golberg, D. Adv. Mater. 2005, 17, 3005 .

(30) Han, W.-Q.; Wu, L.; Zhu, Y. J. Am. Chem. Soc. 2005, 127, 1281412815 .

(31) Zhou, K.; Yang, Z.; Yang, S. E. N. Chem. Mater. 2007, 19, 12151217.

(32) Chen, G.; Xu, C.; Song, X.; Zhao, W.; Ding, Y.; Sun, S. Inorg. Chem. 2008, 47, 723-728.

(33) Yuan, Q.; Liu, Q.; Song, W.-G.; Feng, W.; Pu, W.-L.; Sun, L.-D.; Zhang, Y.-W.; Yan, C.-H. J. Am. Chem. Soc. 2007, 129, 6698-6699.

(34) Si, R.; Zhang, Y.-W.; Li, S.-J.; Lin, B.-X.; Yan, C.-H. J.Phvs. Chem. B 2004, 108, 12481-12488.

(35) Fan, H. J.; Knez, M.; Scholz, R.; Hesse, D.; Nielsch, K.; Zacharias, M.; Go1sele, U. Nano Lett. 2007, 7, 993-997.

(36) Raidongia, K.; Rao, C. N. R. J.Phvs. Chem. C 2008, 112, 1336613371.

(37) Zhou, K.; Wang, X.; Sun, X.; Peng, Q.; Li, Y. J. Catal. 2005, 229, 206.

(38) Zhang, C. P. D.; Shi, L. J. Solid State Chem. 2008, 181, 12981306.

(39) Trovarelli, A. Catalvsis bv Ceria and Related Materials: Imperial College Press: London, 2002.

(40) Zhou, K. B.; Wang, X.; Sun, X. M.; Peng, Q.; Li, Y. D. J. Catal. 2005, 229, 206.

(41) Andreeva, D.; Ivanov, I.; Ilieva, L.; Abrashev, M. V. Appl. Catal. A 2006, 302, 127-132.

JP810492S 